\title{
Maltese Students' Perspectives About Their Experiences at School and Their Mental Health
}

\author{
Helen Askell-Williams, ${ }^{1}$ Carmel Cefai, ${ }^{2}$ and Francis Fabri ${ }^{3}$ \\ 1 Flinders Educational Futures Research Institute, School of Education, Flinders University, Adelaide, \\ South Australia, Australia \\ 2 EuroCentre for Educational Resilience and Socio-Emotional Health, University of Malta, Malta \\ 3 Research and Development Department, Ministry of Education and Employment, Malta
}

In this article we report Maltese primary and secondary students' perspectives about their school experiences and their mental health. Questionnaires were completed by 281 students. Relationships emerged between students' reports about their involvement in bullying, mental health status, and a range of typical features of school environments. A conservative non-parametric JonckheereTerpstra test indicated significant unidirectional differences, from non-involved through to bully/victim groups, for six selected variables that have the potential to be influenced by schools' policies and practices, namely, positive school community, coping with school work, social and emotional education, friendships, safety, and teachers' responses to bullying events. Effect sizes ranged from small to medium. This study illustrates identifiable patterns of students' social, emotional and academic wellbeing. It highlights the need for intervention programs that are conceptualised to meet the needs of different student groups, in this case, involvement in bullying as a victim or as a bully. It also highlights how a range of school-based influences may operate together to affect the wellbeing of students, and points to the need for multi-disciplinary collaboration and approaches to mental health promotion in schools.

Keywords: students' perspectives, victims and bullies, mental health

Students' lives at school consist of many components, including engagement with their school community, success at learning endeavours, positive relationships with teachers and peers, developing social and emotional competencies, and coping with negative influences such as bullying/harassment. These varied components of students' lives are reflected in the mission statements of schools, which recognise that students' wellbeing and learning cannot be separated. For example, the South Australian Department of Education and Child Development (DECD) provides the Learner Wellbeing Framework (DECD, 2012), which calls for schools to attend to

ADDRESS FOR CORRESPONDENCE: Helen Askell-Williams, School of Education. Flinders University, GPO Box 2100, Adelaide, South Australia, 5001. Email: helen.askell-williams@flinders.edu.au 
the emotional, physical, social, cognitive and spiritual dimensions of students' lives. Similarly, on the other side of the globe, the Maltese National Curriculum Framework for All (MEEF, 2012) values the role of social and emotional dimensions in education from the early years, drawn from insights provided by the international literature on emotional intelligence, emotional literacy and social and emotional learning.

\section{Academic Achievement}

Brand, Reimer, and Opwis (2007) showed that people don't learn as well in a negative mood. Similarly, a study by Roeser, Eccles, and Strobel (1998) showed that students' emotional distress negatively predicted their academic achievement (controlling for motivation, prior achievement, and socio-demographic characteristics). In their meta-analysis of over 200 studies, Durlak, Weissberg, Dymnicki, Taylor, and Schellinger (2011) found that students who participated in universal social and emotional learning programs scored significantly higher on standardised achievement tests when compared to peers not participating in the programs. Their study indicates that any perceived extra work on the part of teachers due to the introduction of social and emotional education can be expected to be rewarded with enhanced student achievement.

Also, students who lack declarative, procedural and conditional knowledge about productive learning strategies, and motivational knowledge, such as attributing success to effort, may find their academic progress hampered (Anderson, 2010; Borkowski, Carr, Rellinger, \& Pressley, 1990; Dweck, 1999; Graham \& Weiner, 1993). This is likely to lead to a loss of self-efficacy for academic work, which can lead to a downward spiral of learning attainments and even poorer self-efficacy ( $\mathrm{Pa}$ jares \& Urdan, 2006; Zimmerman, 2000). For example, Roeser, van der Wolf and Strobel (2001) reported that early adolescents' self-efficacious expectancy of success and valuing of subject-matter was positively related to their academic achievement. In a national study in Maltese schools, Cefai, Cooper, and Camilleri (2008) reported that students' lack of academic engagement was the strongest predictor of social, emotional and behavioural difficulties, underlining the inextricable link between the academic and social-emotional components of students' lives at school. As Roeser et al. (1998) argued, it is important to study educational and mental health issues simultaneously as there is, at least for some children, a co-occurrence of academic problems and emotional distress.

\section{Bullying}

Students' involvement in bullying has received attention in recent years as a substantial cause of emotional distress. For example, Skrzypiec, Slee, Askell-Williams, and Lawson (2012) found links between young adolescent students' mental health difficulties and involvement in bullying. In that study, approximately one-quarter of students in the bully-victim group, and one in five students in the victim group, scored in the abnormal range of the Strengths and Difficulties Questionnaire (SDQ), a broad measure of mental health difficulties (Goodman, 2005). The authors compared these figures to statistics from the general population, where approximately one in seven adolescents (in Australia) are reported to experience mental health 
or behavioural difficulties. Similarly, in a study of 123,227 students aged 11, 13 and 15 years across 28 countries (in eastern and western Europe, Scandinavia, North America, Israel and Russia), Due et al. (2005) found significant associations between victimisation and psychological symptoms such as feeling nervous, feeling low, loneliness and helplessness. Victims experience a high risk for psychosomatic complaints and depression (Fekkes, Pijpers, \& Verloove-Vanhorick, 2004; Juvonen, Graham, \& Schuster, 2003; Menesini, Modena, \& Tani, 2009; Veenstra et al., 2005). For example, a study of over 26,000 Finnish adolescents found that involvement in bullying was associated with a range of mental health problems such as anxiety, depression and psychosomatic symptoms (Kaltiala-Heino, Rimpela, Rantanen, \& Rimpela, 2000). In a longitudinal study with Maltese children, Cefai and Camilleri (2011) found that increases in social, emotional and mental health difficulties were more likely to occur for pupils attending schools where bullying was prevalent. In that study, school bullying was the strongest whole school predictor of social, emotional and behavioural difficulties among young children.

\section{Friendships}

Studies indicate that friendships operate in interaction with bullying. Victims of bullying report having fewer friends than their classmates (Veenstra et al., 2005). Similarly, Hodges, Malone, and Perry (1997) reported that the number of friends held by a young person was negatively correlated with being victimised. Recently, Skrzypiec et al. (2012) found a three-way relationship, whereby the likelihood of obtaining an abnormal mental health difficulties score on the SDQ decreased with an increasing number of good friends for students in victim, bully and bully-victim groups.

\section{Interventions for Mental Health Promotion}

Contemporary school-based models for mental health promotion advocate that mental health is a function, at the micro-level, of the psychological world of each child; at the meso-level, of close settings such as families; and at broader macrosettings, such as schools, community facilities and government policies (Graetz et al., 2008). This indicates that risk and protective factors within school settings may operate to either exacerbate or minimise students' mental health difficulties.

Recognising the macro-level influence of schools, frameworks for mental health promotion initiatives in schools are typically founded in a whole school approach, with focused attention on developing school policies, improving social relationships, and building individual competencies (Adi, Killoran, Janmohamend, \& Stewart-Brown, 2007; Greenberg, 2010; Weare \& Nind, 2011). These efforts are relevant to teachers as well as to students. School policies and individual teachers' perceptions about the role of teachers in, say, intervening in bullying, determine whether a school might operate as a social determinant of mental health, or mental ill-health. Similarly, the social and emotional education curriculum of a school has the potential to build students' capabilities to establish friendships with their peers, and to learn productive strategies for coping with bullying.

Social and emotional education is considered to be a core component of mental health promotion initiatives. There are now many social and emotional education 
programs delivered in schools. For example, in the United States, the Collaborative for Academic, Social and Emotional Learning (CASEL, 2011b) has driven substantial reforms that demand attention to the social and emotional lives of students, including self-awareness, social awareness, self-management, relationship skills, and responsible decision making. Similarly, in the United Kingdom, initiatives such as the Social and Emotional Aspects of Learning (SEAL) program address a range of students' developmental needs (Department for Children, Schools and Families, 2009). In Australia there are also numerous curriculum initiatives for social and emotional education, and specific policy initiatives for mental health promotion. For example, the KidsMatter (2012c) mental health promotion initiatives focus upon four components that can be influenced at the school level, namely, building a positive school community, providing social and emotional education for all students, providing support for parenting, and early intervention for students at risk. In Malta, Personal and Social Education, Nurture Groups, Circle Time and Learning Support Zones, and related initiatives have been introduced in primary and secondary schools to promote mental health and emotional literacy for young people (Cefai, Grech, Mallia, \& Borg, 2011; Fabri \& Bezzina, 2010).

Of course, not all students experience academic, social, emotional or mental health difficulties. And for those who do experience difficulties, patterns of influences and needs for intervention are conceivably different. To account for individual needs, Fuchs (2006) has proposed more precise profiling of students' characteristics in order to maximise the allocation of resources to school-based interventions. Hence the present article seeks to understand more about patterns of influences that affect students' lives at school.

\section{The Maltese Context}

Our interest in this article lies with students in Maltese schools, and so we turn to reports from Malta. A national study reported by Cefai et al., (2008) found that about $10 \%$ of the Maltese student population experienced social, emotional and/or behavioural problems. In a World Health Organization (WHO, 2008) international comparative study, Maltese students rated their health and wellbeing relatively poorly. They reported that they felt among the most pressured students in the study, with the pressure increasing across the secondary school years (WHO, 2008). In that study, although school-based bullying in Malta was reported to be lower than the European Union (EU) average, violence was reported to be well above the EU average, particularly among 13- to 15 -year-old students (WHO, 2008). A study among OECD countries suggested that almost half of lower secondary students in Malta intimidated or verbally abused other students, which was significantly higher than the study average (OECD, 2009). In a study with Maltese primary school children, bullying at school was one of the strongest predictors of social, emotional and behavioural problems and mental health difficulties (Cefai \& Camilleri, 2011).

It is in this Maltese context that we address the following research questions:

1. What are students' perceptions of their academic motivations, learning strategies, mental health, friendships, coping with bullying and school environments?

2. In what ways do these perceptions differ according to students' involvement in bullying? 


\section{Method}

\section{Ethics}

Ethics approvals were obtained from the University Research Ethics Committees, the Maltese Education Directorate, the College Principal and Heads of Schools. Consent to participate was gained from students and their parents. Participation was informed, voluntary and anonymous.

\section{Student Questionnaires}

Students are a valuable source of information about the impact of features of school settings on their lives. By listening to students' voices, we can learn what is working well and not so well, from their points of view (Cefai \& Cooper, 2011; Cooper \& McIntyre, 1996; Rudduck, Day, \& Wallace, 1997; Rudduck \& Flutter, 2000). For example, Fabri (2011) provided evidence that Maltese students are aware of, and can usefully reflect upon, a number of interacting components that impact upon their school lives.

Students were administered the Living and Learning at School questionnaire. The questionnaire was purpose designed, drawing where possible from existing, validated, questionnaires. The items about positive school community were drawn from the KidsMatter Primary mental health promotion initiative evaluation (Slee et al., 2009). Items about social and emotional learning were constructed from the components outlined by the CASEL (2011b). Items about peer relationships and bullying were drawn from the Peer Relations Questionnaire (Rigby \& Slee, 1993). The design of the motivation and learning items drew from Mayer's (1998) framework of motivation, cognition, and metacognition, and from existing questionnaires and checklists (e.g., PALS, Midgley et al., 2000; MSLQ, Pintrich \& DeGroot, 1990; SEM, Schraw \& Dennison, 1994). The items about positive mental health were drawn from CASEL, while the items about mental health difficulties were adapted from information provided by SANE (n.d.) and beyondblue, the national depression initiative (2013).

We translated the questionnaire items from English into Maltese. The translation was undertaken by the second author and then independently verified against the English version by two Maltese/English speaking teachers. Minor changes were made following verification, until all three translators agreed upon the final translation.

Responses to each question were on Likert scales, with scale anchors typically of very strongly disagree to very strongly agree, or never to always. The Appendix provides summary details about the questionnaire items and scales.

\section{Sampling Design}

Heads of schools of the four primary schools and three secondary schools comprising one of Malta's 10 state district colleges agreed to participate. We determined that the level of reading difficulty of the items in the questionnaire would be suitable for students in Grade 5 and above. We were advised by the schools that students in Grades 11 and 12 were unavailable due to their need to prepare for examinations. Therefore, the sample consisted of students from Grades 5 to 10. Each school provided a de-identified (numerical IDs) enrolment list of their students in the relevant 
grade levels. This identified that there were 1,465 students in the sampling frame. As we needed to work within budgetary, time and statistical constraints, we assessed that we would like to achieve a sample of 300 students (for a confidence level of $95 \%$ and a confidence interval of $5 \%$ ). Using SPSS, a random sample of a base of 40 students plus $6 \%$ of the remaining students was selected from each school enrolment list. In the co-educational primary schools, equal numbers of boys and girls were selected. The secondary schools contained either all girls or all boys. An identified contact person in each school was asked to match the selected de-identified IDs to their confidential list of student names. Questionnaires were delivered to students via the school contact person and returned in anonymous, sealed envelopes to the school and then to the researchers.

\section{Data Preparation}

Of the 360 questionnaires delivered, 281 were returned, giving a response rate of $78 \% .{ }^{1}$ Missing data was less than $1 \%$ per question, and was not replaced. Girls comprised $49.5 \%$ of the sample. Students' ages ranged from 10 to 15 years, with a median age of 11.3 years.

To enable comparisons between items measured on different scales, all single items were standardised for use in subsequent analyses. Principal Components Analysis and Reliability Analysis routines were run on thematic groups of items, and confirmed the original conceptual design and selection of items for each theme. ${ }^{2}$ For the items that were thematically grouped, factor scores generated by the PCA were used for subsequent analyses.

\section{Results}

We used students' scores on the Peer Relationships scale to classify students into four groups, as follows: not involved in bullying (139 students), bullies (29), victims (56), and both bullies and victims (35). Figure 1 displays the frequencies of Involvement in Bullying by Gender and Grade. Around one-quarter to one-half of students were involved in bullying in most grades, but fewer in Grades 8 and 10. The distribution of boys and girls across the Involvement in Bullying groups was similar, $\chi^{2}(3)=4.95$ ns.

To investigate whether there were identifiable patterns of responses to the variables in the questionnaire we created profiles of the four groups' mean scores on each variable. The profiles, displayed in Figure 2, show consistent patterns of reported difficulties for students involved in bullying across the broad range of influences in school settings.

Starting from the left of Figure 2, bully/victims have low scores on the items related to engagement with school, motivation and learning. Bullies also show lower scores than victims and non-involved students on the motivation and learning strategies scales. Whereas bully/victims and victims have less desirable scores over the range of variables in this section of Figure 2, it is notable that for the Learning Strategies factor this trend is reversed, with bullies and bully/victims having relatively low scores, but victims scoring similarly to non-involved students. This finding could point to an influence on bullies of poor self-regulatory skills, both for learning and for emotional control. 


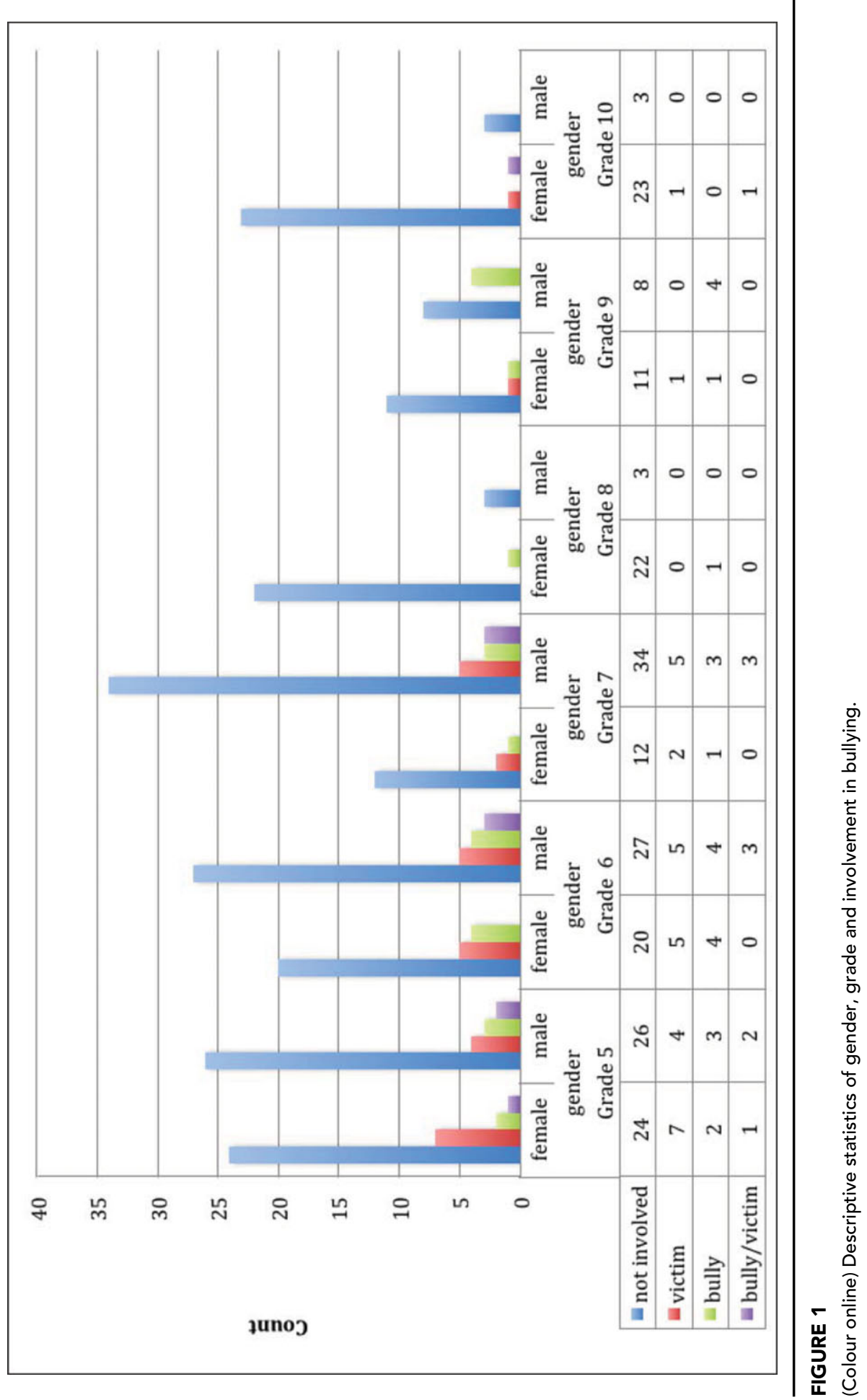




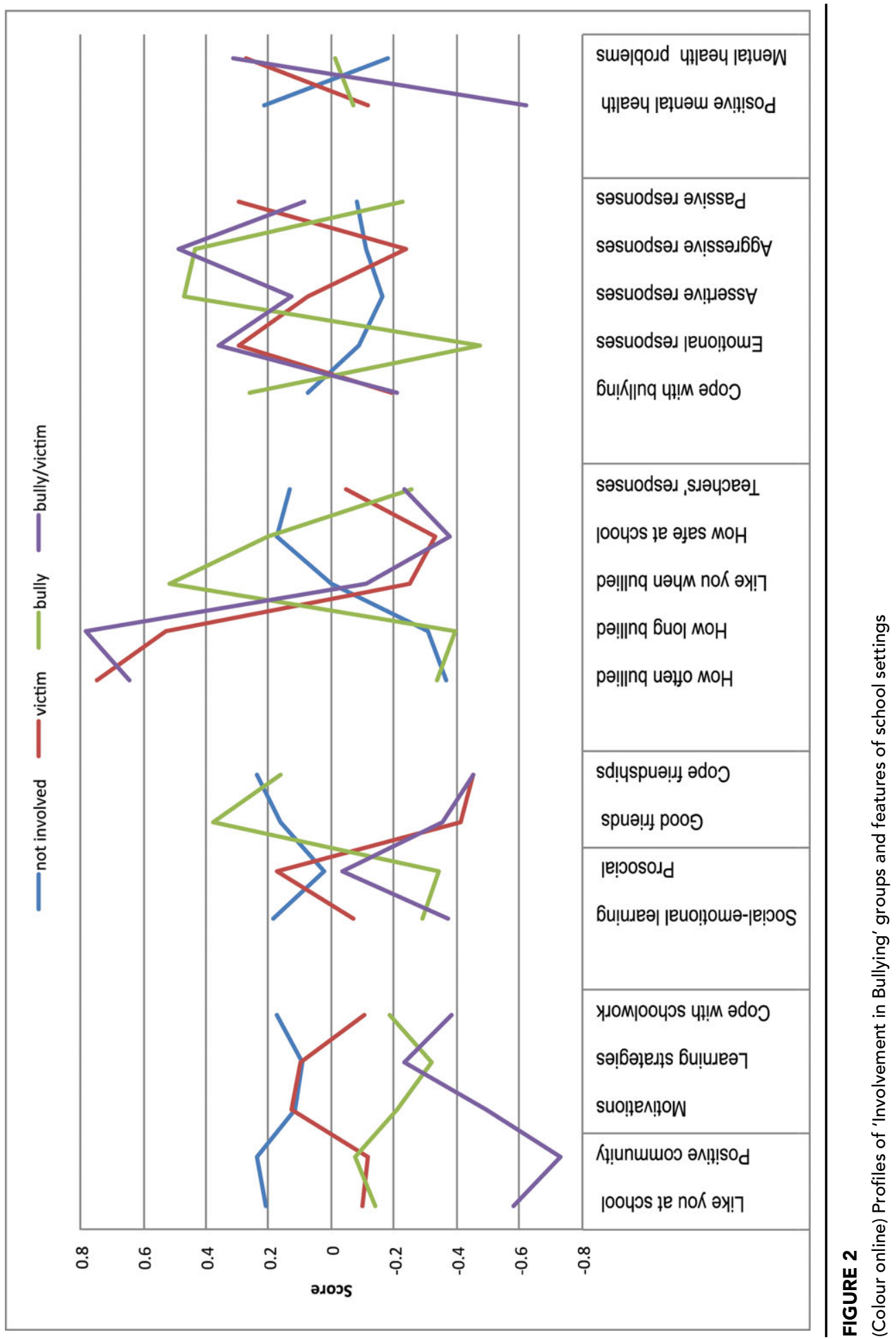


In the second section from the left of Figure 2, the three groups involved in bullying show relatively lower scores on measures of social skills and friendships, with the exception of victims who rated themselves higher on pro-social strategies, and bullies, who claim to have the most friends. Bullies' claims about having more friends was also found by Skrzypiec et al. (2012) in a study with Australian students. Bullies also show similarity with non-involved students in their rating of their ability to cope with friendships at school. These findings about bullies' perceptions of their friendship status raises interesting questions about the quality of friendships, and whether peers are genuinely friendly with bullies, or use such friendships as a protective factor.

In the third section of Figure 2, the frequency and duration of bullying is in expected directions given the classification of students into the four groups. Noteworthy are students' responses to the question about Feeling safe from bullying, where victims and bully/victims feel less safe, but bullies score at the same level as students not involved in bullying. The response from bullies to the item, Like you when being bullied, appears peculiar, as it indicates that bullies, on average, were not unhappy if they were bullied. This points to the complex social and emotional goals that bullies might satisfy through bullying. The finding is similar to Borg's (1998) study of 6,282 students in Maltese schools, which found that whereas victims experienced mostly feelings of vengefulness, anger and self-pity, bullies were mainly sorry or indifferent. The final item in this section of Figure 2 indicates that, compared to students not involved in bullying, students in all three involved groups consider that Teachers respond to bullying less often. This latter finding could indicate, at least in part, teachers' attitudes towards bullying and the effectiveness of school bullying policies.

The fourth section of Figure 2 shows students' accounts of their different strategies for coping with bullying. Bullies seem to consider themselves more able to cope than the other groups, resorting to emotional and passive responses less often, and assertive and aggressive responses more often. Victims and bully/victims score more highly on emotional responses, and it is interesting that bully/victims also score relatively highly on aggressive responses. These preferred responses to bullying can be compared to work by Murray-Harvey, Skrzypiec, and Slee (2012), whose study of the views of expert researchers' and practitioners' in bullying prevention programs clearly indicated that assertive responses to bullying are the most productive.

Finally, to the far right of Figure 2, bully/victims show the lowest positive mental health and the highest mental health difficulties. This trend is in the same direction, but less steep, for bullies and victims, and reversed for non-involved students. These relationships between bullying and mental health are consistent with findings in the literature (e.g., Cefai \& Camilleri, 2011; Slee \& Murray-Harvey, 2011). The more extreme scores for bully/victims highlights that this group of students may be particularly vulnerable.

The profiles displayed in Figure 2 clearly show that students involved in bullying report a range of difficulties. The next question that arises is whether these differences are of substantive significance.

As expected, most participants were classified in the non-involved in bullying group, and responded in positive directions on the questionnaire variables. This caused most of the responses to violate assumptions of normal distribution, and 
thus be unsuitable for parametric tests. Also, it would be undesirable to concurrently test the significance of such a large number of variables in the same study, as this could lead to an increased chance of obtaining significant results due to conducting many tests (Field, 2006).

We therefore decided to investigate differences between the four student groups on a selected set of variables. We identified six variables, two from each of the first three sections of Figure 2, that are within the power of schools to directly influence; namely, Positive School Community, Cope with School Work, Social \& Emotional Education, Cope with Friendships, How Safe, and Teachers' Responses When They See Bullying. As we were conducting six concurrent tests of significance, we applied a Bonferroni correction to the usual $p<.05$ level of acceptance of a significant effect, giving $p<.008$ as the benchmark for this study (Field, 2006).

We used the non-parametric Jonckheere-Terpstra test in SPSS to investigate differences among the four groups' median scores on the six variables, and also whether the order of those medians was meaningful. Based on the profiles displayed in Figure 1, we hypothesised that the medians would follow the order of non-involved, victim, bully, and bully/victim. Table 1 shows that the JonckheereTerpstra tests revealed significant trends in the data for all six variables. As predicted, as involvement in bullying escalated, from non-involved through to being both a bully and a victim, students reported significantly less desirable responses to the six measured aspects of their lives at school. Effect sizes were small, except for Positive School Community, which was medium. Note however that small effects, repeated across communities and cumulative across time, can amount to practically important impacts.

\section{Discussion}

This article uses students' reports about their lives at school to create profiles of students' involvement in bullying, their mental health, and 19 features of school settings. The prevalence of bullying reported by students in our study is similar to earlier reports about Maltese and Australian school students. For example, Borg (1998) found that one in three Maltese students were involved in bullying as a victim or perpetrator. And in an Australian study, Cross et al. (2009) reported that approximately one in four Year 4 to Year 9 students reported being bullied, overtly and/or covertly, every few weeks or more often.

The profiles illustrate that subgroups of students experience recognisable patterns of responses to features of school environments. Students who reported being involved in bullying also reported experiencing a range of school events in more detrimental ways than students not involved in bullying. Of particular note are the more extreme responses from bully/victims to some variables, such as emotions, safety, coping and mental health. As Skrzypiec et al. (2012) noted, bully/victims have some responses in common with bullies, and some in common with victims. The present study indicates that these commonalities consistently err on the side of more disadvantageous perceptions of school life for bully/victims, and are associated with relatively more poor scores for both mental health difficulties and mental health strengths. 
TABLE 1

Significance of Associations Between Bullying Group and Six Variables

\begin{tabular}{lcccccccc}
\hline & $N$ & Observed J-T & Mean J-T statistic & SD J-T statistic & $z$ score & Sig.1-tailed & $r$ & Effect size \\
\hline Positive school community & 281 & 9018.5 & 12597 & 718.357 & -4.982 & 0.000 & -.30 & Medium \\
Cope with school work & 268 & 9629.5 & 11309.5 & 624.633 & -2.690 & 0.004 & -.16 & Small \\
Social \& emotional learning & 281 & 10031 & 12597 & 718.544 & -3.571 & 0.000 & -.21 & Small \\
Cope with friendships & 255 & 8222 & 10193.5 & 557.473 & -3.536 & 0.000 & -.22 & Small \\
How safe from bullying & 274 & 10090 & 11997.5 & 657.626 & -2.901 & 0.002 & -.18 & Small \\
What do teachers do & 269 & 10121 & 11437 & 547.134 & -2.405 & 0.008 & -.15 & Small \\
\hline
\end{tabular}

Note: Effect sizes: small $=r>.1$, medium, $r>.24$; large $r>.37$ (Kirk, $1996 \# 1842$ ) 
The six variables selected for the Jonckheere-Terpstra test have the potential to be within the control of teachers, schools and school systems. It would not be difficult to find intervention programs that deal with one, two or a few, of these areas. For example, the KidsMatter Mental Health Promotion Initiative in Australia identifies four areas for intervention; namely, building a positive school community, social and emotional education for all students, parenting education and support, and early intervention for students at risk or experiencing difficulties (KidsMatter, 2012 a p. 6). Within that broad framework, KidsMatter schools can choose intervention programs that suit their own contexts. Thus, some schools might select an intervention program that has more emphasis on the psychological world of the child, while others might select a program that has more emphasis on system-level determinants. Our reading of the KidsMatter Programs Guide (2012b) suggests that it may be difficult to find programs that integrate social, emotional, motivational and academic components, at individual, school and family/community levels. It is this need for integrated attention to various influences that is highlighted by our study. This is consistent with the concerns raised by Cooper (2011), who proposed that popular programs, such as Circle Time, may be undermined if the need to embed the initiative within a broader range of school influences is ignored. Cooper argued that simply implementing the visible features of a program — for example, in the case of Circle Time, enabling students to share their thoughts and feelings in a non-judgmental atmosphere - is insufficient. Rather, programs such as Circle Time must be understood and embedded within a supportive humanistic approach in the whole-school social, emotional and academic environment. For example, in a study in Maltese primary school classrooms, Cefai, Cooper, and Camilleri (2008) found that schools that promoted caring classrooms and communities were more likely to have students who demonstrated pro-social, inclusive and collaborative behaviours. Also from a study in Malta, Cefai and Camilleri (2011) suggested that interventions to prevent social, emotional and behavioural difficulties in school, including bullying behaviours, need to be multifaceted, including individual, classroom, whole school and family factors. Cefai and Camilleri found that the most salient predictors of prosocial behavior included caring and supportive relationships with teachers, supportive peer groups, engagement in the learning process, and schools with low levels of bullying and pupil fighting.

\section{Implications}

The profiles uncovered in our study raise further questions. The first is the clear relationship between students' reports of being involved in bullying and their mental health. Recognising the seriousness of possible links between involvement in bullying and mental health, Lieberman and Cowan (2011) and Skrzypiec et al. (2012) recommended that children and teens who are frequently involved in bullying behaviour, either as victims or as perpetrators, should be actively screened for mental health problems. The profiles generated from participants' reports in our study lend support to that recommendation.

A second issue is whether bullies', victims' and bully/victims' responses to questions about issues such as coping with schoolwork and coping with friendships indicate that these different student groups might require differently conceptualised 
intervention programs. Whole school approaches are recommended in order to raise levels of awareness and strategies for dealing with bullying (Safe and Supportive School Communities Working Group, 2013), and for developing social-emotional and academic skills (CASEL, 2011a). Our study provides evidence that more differentiated programs may be needed alongside whole school approaches, which is consistent with advice from Greenberg (2010) and Weare and Nind (2011). For example, bullies may construe good friends in different ways to victims, and may need to build their social skills from potentially different underlying assumptions about friendships. Similarly, perhaps explicit teaching about taking an empathetic perspective is more relevant to students who engage in bullying others. It is notable that students in the Bully group reported that they were not necessarily unhappy when being bullied themselves. And yet, the lower reported levels by the Bully group to other variables in this study, such as mental health and coping with school work, indicate a much more complicated picture of bullies' lives at school that might belie claims about not being unhappy about being bullied. Perhaps bravado influenced students' responses (and are a limitation of self-reports, as discussed in the limitations section below).

In the academic domain, victims may be suffering at school, but nevertheless may have relatively good learning strategies, motivational dispositions and selfregulatory skills. However, bullies, with arguably poor skills of self-regulation, may see the effects of that poor self-regulation played out not only in their social relationships but also in their academic endeavours and their emotional control. Hence, explicit teaching of productive learning strategies, effort-based attributions and self-regulatory strategies may be of particular benefit for students exhibiting bullying behaviours. However, caution would need to be exercised with the introduction of more differentiated intervention programs in order to avoid dangers associated with labelling students as bullies or victims.

The relatively low responses from all three groups of students involved in bullying about Teachers' responses and Feeling safe send clear messages about the importance of regularly reviewing school policies and procedures about acceptable behaviours in class and in school grounds. Individual teachers' perceptions of which behaviours constitute bullying/harassment need to be openly discussed in conjunction with the establishment of schools' bullying policies. A related issue is whether the agreed school policies and procedures are visible and accessible to the students.

\section{Conclusions}

Roeser and Eccles (2000) argued that if we know more about how issues particular to school contexts interact with children's social and emotional health, then we can provide better policy and practice advice to educational policy-makers and practitioners. In our study, students belonging to identifiable groups of involvement in bullying show similar patterns of responses to questions about a range of features of their lives at school. Promotion and prevention programs that provide integrated attention to students' emotional, social and academic needs, at whole school and subgroup levels, appear warranted. This will require input from a range 
of professional groups, including teachers, curriculum designers, school counselors, psychologists and social workers.

\section{Limitations}

This study included Maltese primary and secondary school students randomly selected from one school district. While there are no apparent reasons to consider that the participants were not typical of Maltese students, the fact that they were not a random sample across the whole Maltese student population is a limitation of the study.

This study used self-report questionnaires. All methods of data collection have limitations (Muijs, 2006). Questionnaires take a broad perspective and may lack contextual sensitivity. Furthermore, self-reports may be coloured by socially desirable responses, self-reflective blind spots, or self-protective attitudes. This may particularly apply to reports of involvement in bullying. Future research in this field could triangulate assessments from other informants such as teachers and parents.

\section{Acknowledgments}

The studies reported in this article were supported by grants from the European Union FP7 Marie Curie International Research Staff Exchange Scheme, the Australian Academy of Science, the Faculty of Education, Humanities and Law at Flinders University and the European Centre for Educational Resilience and SocioEmotional Health at the University of Malta. We would like to thank the heads of schools, teachers and students who willingly contributed their time and perspectives to this study

\section{Endnotes}

1 The results section discusses our selection of conservative non-parametric tests that accommodate this response rate.

2 Details of the Principal Components Analyses and Reliability Analyses can be obtained from the corresponding author.

\section{References}

Adi, Y., Killoran, A., Janmohamend, K., \& Stewart-Brown, S. (2007). Systematic review of interventions to promote mental wellbeing in children in primary education: Report 1: Universal approaches (non-violence related outcomes). London: National Institute of Health and Clinical Excellence.

Anderson, J.R. (2010). Cognitive psychology and its implications (7th ed.). New York: Worth.

beyondblue. (2013). Home page. Retrieved Feb 15, 2013, from http://www.beyondblue. org.au/index.aspx?

Borg, M.G. (1998). The emotional reactions of school bullies and their victims. Educational Psychology, 18, 433-444. doi:10.1080/0144341980180405

Borkowski, J.G., Carr, M., Rellinger, E., \& Pressley, M. (1990). Self-regulated cognition: Interdependence of metacognition, attributions, and self-esteem. In B.F. Jones 
\& L. Idol (Eds.), Dimensions of thinking and cognitive instruction (pp. 53-92). Hillsdale, NJ: Erlbaum.

Brand, S., Reimer, T., \& Opwis, K. (2007). How do we learn in a negative mood? Effects of a negative mood on transfer and learning. Learning and Instruction, 17, 1-16. doi:10.1016/j.learninstruc.2006.11.002

Cefai, C., \& Camilleri, L. (2011). Building resilience in school children. Risk and promotive factors amongst Maltese primary school pupils. Malta: European Centre for Emotional Resilience and Socio-Emotional Health.

Cefai, C., \& Cooper, P. (2011). Nurture Groups in Maltese schools: Promoting inclusive education. British Journal of Special Education, 38, 65-72. doi:10.1111/j.14678578.2011.00500.x

Cefai, C., Cooper, P., \& Camilleri, L. (2008). Engagement time: A national study of students with social, emotional and behaviour difficulties in Maltese schools. Malta: European Centre for Education Resilience and Socio-Emotional Health, University of Malta.

Cefai, C., Grech, T., Mallia, C., \& Borg, F. (2011). Education with heart. Social and emotional education as a core competence in Maltese primary schools. Malta: European Centre for Education Resilience and Socio-Emotional Health, University of Malta.

Collaborative for Academic, Social and Emotional Learning (CASEL). (2011a). Programs in action. Retrieved July 17, 2013, from http://casel.org/in-schools/selectingprograms/programs-in-action/

Collaborative for Academic, Social and Emotional Learning (CASEL). (2011b). What is SEL? Retrieved March 31, 2013, from http://casel.org/why-it-matters/what-is-sel/

Cooper, P. (2011). Educational and psychological interventions for promoting socialemotional competence in school students. In P. Slee, R. Murray-Harvey, \& K. Dix (Eds.), Mental health and wellbeing: Educational perspectives (pp. 29-40). Adelaide, Australia: Shannon Research Press.

Cooper, P., \& McIntyre, D. (1996). Effective teaching and learning: Teachers' and students' perspectives. Buckingham, UK: Open University Press.

Cross, D., Shaw, T., Hearn, L., Epstein, M., Monks, H., Lester, L., \& Thomas, L. (2009). Australian covert bullying prevalence study (ACBPS). Perth, Australia: Child Health Promotion Research Centre, Edith Cowan University.

Department for Children, Schools and Families (DCSF). (2009). Promoting and supporting positive behaviour in primary schools. Developing social and emotional aspects of learning (SEAL). Nottingham, UK: Author.

Department for Education and Child Development (DECD). (2012). Learner wellbeing framework for birth to Year 12. Retrieved March 29, 2013, from http://www.decd.sa.gov.au/learnerwellbeing/pages/frame/framework/?reFlag=1

Due, P., Holstein, B.E., Lynch, J., Diderichsen, F., Gabhain, S.N., Scheidt, P., ... Health Behaviour in School-Aged Children Bullying Working Group. (2005). Bullying and symptoms among school-aged children: International comparative cross sectional study in 28 countries. European Journal of Public Health, 15, 128-132. doi:10.1093/eurpub/cki105

Durlak, J.A., Weissberg, R.P., Dymnicki, A.B., Taylor, R.D., \& Schellinger, K.B. (2011). The impact of enhancing students' social and emotional learning: A metaanalysis of school-based universal interventions. Child Development, 82, 405-432. doi:10.1111/j.1467-8624.2010.01564.x 
Dweck, C. (1999). Self theories: Their role in motivation, personality and development. Philadelphia, PA: Psychology Press.

Fabri, F. (Ed.). (2011). Ittra lill-Principal tal-Kulleg் $\dot{g}$ u oちra lill-Istudenti. Malta: Kulleg் Santa Tereża.

Fabri, F., \& Bezzina, C. (Eds.). (2010). School improvement through school networks: The Malta experience. Malta: Ministry of Education, Employment and the Family.

Fekkes, M., Pijpers, F.I.M., \& Verloove-Vanhorick, S.P. (2004). Bullying behavior and associations with psychosomatic complaints and depression in victims. Journal of Pediatrics, 144, 17-22. doi:10.1016/j.jpeds.2003.09.025

Field, A. (2006). Discovering statistics using SPSS (3rd ed.). London: Sage.

Fuchs, D. (2006). Cognitive profiling of children with genetic disorders and the search for a scientific basis of differentiated education. In P.A. Alexander \& P.H. Winne (Eds.), Handbook of educational psychology (2nd ed., pp. 187-206). Mahwah, NJ: Erlbaum.

Goodman, R. (2005). Strengths and Difficulties Questionnaire. Retrieved February 1, 2011, from http://www.sdqinfo.org/py/doc/b3.py?language=Englishqz(Austral)

Graetz, B., Littlefield, L., Trinder, M., Dobia, B., Souter, M., Champion, C., ... Cummins, R. (2008). KidsMatter: A population health model to support student mental health and well-being in primary schools. International Journal of Mental Health Promotion, 10(4), 13-20. doi:10.1080/14623730.2008.9721772

Graham, S., \& Weiner, B. (1993). Attributional applications in the classroom. In T.M. Tomlinson (Ed.), Motivating students to learn (pp. 179-196). Berkeley, CA: McCutchan.

Greenberg, M.T. (2010). School-based prevention: Current status and future challenges. Effective Education, 2, 27-52. doi:10.1080/19415531003616862

Hodges, E.V.E., Malone, M.J.J., \& Perry, D.G. (1997). Individual risk and social risk as interacting determinants of victimization in the peer group. Developmental Psychology, 33, 1032-1039. doi:10.1037/0012-1649.33.6.1032

Juvonen, J., Graham, S., \& Schuster, M.A. (2003). Bullying among young adolescents: The strong, the weak, and the troubled. Pediatrics, 112, 1231-1237. doi:10.1542/peds.112.6.1231

Kaltiala-Heino, R., Rimpela, M., Rantanen, P., \& Rimpela, A. (2000). Bullying at school - An indicator of adolescents at risk for mental disorders. Journal of Adolescence, 23, 661-674. doi:10.1006/jado.2000.0351

KidsMatter. (2012a). The Framework. Retrieved March 31, 2013, from http://www. kidsmatter.edu.au/primary/about-kidsmatter-primary/framework

KidsMatter. (2012b). KidsMatter SEL programs guide. Retrieved March 12, 2013, from http://www.kidsmatter.edu.au/primary/resources-your-journey/otherresources/sel-programs-guide

KidsMatter. (2012c). KidsMatter: Growing healthy minds. Retrieved Feb 1, 2013, from http://www.kidsmatter.edu.au

Lieberman, R., \& Cowan, K.C. (2011). Bullying and youth suicide: Breaking the connection. Principal Leadership, October, 12-17.

Mayer, R.E. (1998). Cognitive, metacognitive, and motivational aspects of problem solving. Instructional Science, 26, 49-63. doi:10.1023/A:1003088013286

MEEF. (2012). A national curriculum framework for all 2012. Retrieved May 22, 2013, from https://http://www.education.gov.mt/News.aspx?newsid=230\&depid=13 
Menesini, E., Modena, M., \& Tani, F. (2009). Bullying and victimization in adolescence: Concurrent and stable roles and psychological health symptoms. Journal of Genetic Psychology, 170, 115-133. doi:10.3200/GNTP.170.2.115-134

Midgley, C., Maehr, M.L., Hruda, L.Z., Anderman, E., Anderman, L., Freeman, K.E., ... Urdan, T. (2000). Manual for the patterns of adaptive learning scales. Retrieved March 31, 2013, from http://www.umich.edu/ pals/manuals.html

Muijs, D. (2006). Measuring teacher effectiveness: Some methodological reflections. Educational Research and Evaluation, 12, 53-74. doi:10.1080/13803610500392236

Murray-Harvey, R., Skrzypiec, G.K., \& Slee, P. (2012). Effective and ineffective coping with bullying strategies as assessed by informed professionals and their use by victimised students. Australian Journal of Guidance and Counselling, 22, 122-138. doi:10.1017/jgc.2012.5

Organisation for Economic Co-operation and Development (OECD). (2009). Teaching and Learning International Survey (TALIS). Retrieved March 31, 2013, from http://www.oecd.org/education/school/43184804.pdf

Pajares, F., \& Urdan, T.C. (2006). Self-efficacy beliefs of adolescents. Greenwich, CN: Information Age.

Pintrich, P.R., \& DeGroot, R. (1990). Motivational and self-regulated learning components of classroom academic performance. Journal of Educational Psychology, 82, 33-40. doi:10.1037/0022-0663.82.1.33

Rigby, K., \& Slee, P.T. (1993). Dimensions of interpersonal relating among Australian school children and their implications for psychological well-being. Journal of Social Psychology, 133, 33-42. doi:10.1080/00224545.1993.9712116

Roeser, R.W., \& Eccles, J.S. (2000). Schooling and mental health. In A.J. Sameroff, M. Lewis, \& S.M. Miller (Eds.), Handbook of developmental psychopathology (2nd ed., pp. 135-156). New York: Kluwer Academic. doi:10.1007/978-1-4615-4163-9_8

Roeser, R.W., Eccles, J.S., \& Strobel, K.R. (1998). Linking the study of schooling and mental health. Educational Psychologist, 33, 153-176. doi:10.1207/ s15326985ep3304_2

Roeser, R.W., van der Wolf, K., \& Strobel, K.R. (2001). On the relation between socialemotional and school functioning during early adolescence: Preliminary findings from Dutch and American samples. Journal of School Psychology, 39, 111-139. doi:10.1016/S0022-4405(01)00060-7

Rudduck, J., Day, J., \& Wallace, G. (1997). Students' perspectives on school improvement. In A. Hargreaves (Ed.), Rethinking educational change with heart and mind (pp. 73-91). Alexandria, VA: ASCD.

Rudduck, J., \& Flutter, J. (2000). Pupil participation and pupil perspective: 'Carving a new order of experience'. Cambridge Journal of Education, 30, 75-85. doi:10.1080/03057640050005780

Safe and Supportive School Communities (SSSC) Working Group. (2013). Bullying. No way! Retrieved July 16, 2013, from http://bullyingnoway.gov.au/teachers/index.html

SANE. (n.d.). SANE Australia. Retrieved February 15, 2013, from http://www.sane.org/ information/about-sane

Schraw, G., \& Dennison, R.S. (1994). Assessing metacognitive awareness. Contemporary Educational Psychology, 19, 460-475. doi:10.1006/ceps.1994. 1033

Skrzypiec, G., Slee, P.T., Askell-Williams, H., \& Lawson, M. J. (2012). Associations between types of involvement in bullying, friendships and mental 
health status Emotional and Behavioural Difficulties, 17, 259-272. doi:10.1080/ 13632752.2012.704312

Slee, P.T., Lawson, M.J., Russell, A., Askell-Williams, H., Dix, K.L., Owens, L., ... Spears, B. (2009). KidsMatter primary evaluation final report. Retrieved May 18, 2013, from http://www.kidsmatter.edu.au

Slee, P.T., \& Murray-Harvey, R. (2011). School bullying: A matter of mental health and wellbeing. In R.H. Shute (Ed.), Mental health and wellbeing: Educational perspectives (pp. 79-90). Adelaide, Australia: Shannon Research Press.

Veenstra, R., Lindenberg, S., Oldehinkel, A.J., De Winter, A.F., Verhulst, F.C., \& Ormal, J. (2005). Bullying and victimization in elementary schools: A comparison of bullies, victims, bully/victims, and uninvolved preadolescents. Developmental Psychology, 41, 672-682. doi:10.1037/0012-1649.41.4.672

Weare, K., \& Nind, M. (2011). Promoting mental health of children and adolescents through schools and school based interventions: Evidence outcomes: School based interventions. Health Promotion International, 26(Suppl. 1), i29-i69. doi: 10.1093/heapro/dar075

World Health Organization (WHO). (2008). Inequalities in young people's health. School-aged children international report from the 2005/2006 survey. Retrieved July 16, 2013, from http:/www.euro.who.int/en/what-we-do/health-topics/ Life-stages/child-and-adolescent-health/publications/2008/inequalities-in-youngpeoples-health.-hbsc-international-report-from-the-20052006-survey

Zimmerman, B.J. (2000). Self-efficacy: An essential motive to learn. Contemporary Educational Psychology, 25, 82-91. doi:10.1006/ceps.1999.1016 


\section{Appendix A}

Themes and Sample Items From the Living and Learning at School in Malta Questionnaire

\begin{tabular}{|c|c|c|c|}
\hline Broad theme & Item or factor & No. items & Sample question \\
\hline \multirow[t]{2}{*}{ School climate } & Emotions & 1 & $\begin{array}{l}\text { Which [emoticon] is most like } \\
\text { you at school? }\end{array}$ \\
\hline & $\begin{array}{l}\text { Positive school } \\
\text { Community }\end{array}$ & 7 & $\begin{array}{l}\text { My school makes me feel } \\
\text { welcome }\end{array}$ \\
\hline \multirow[t]{3}{*}{ School work } & Motivation & 5 & $\begin{array}{l}\text { I am sure that I can do well at } \\
\text { school }\end{array}$ \\
\hline & Learning strategies & 6 & $\begin{array}{l}\text { When I don't understand } \\
\text { something I go back over it } \\
\text { again. }\end{array}$ \\
\hline & $\begin{array}{l}\text { Coping with school } \\
\text { work }\end{array}$ & 1 & $\begin{array}{l}\text { Overall, how well do you } \\
\text { cope with school work? }\end{array}$ \\
\hline \multirow[t]{2}{*}{$\begin{array}{l}\text { Social-emotional } \\
\text { wellbeing }\end{array}$} & $\begin{array}{l}\text { Social and emotional } \\
\text { learning }\end{array}$ & 9 & $\begin{array}{l}\text { The teachers help me to } \\
\text { manage my own emotions }\end{array}$ \\
\hline & Prosocial strategies & 4 & I share things with others. \\
\hline \multirow[t]{2}{*}{ Friendships } & Friendships & 1 & $\begin{array}{l}\text { How many good friends do } \\
\text { you have at your school? }\end{array}$ \\
\hline & Coping with friendships & 1 & $\begin{array}{l}\text { Overall, how well do you } \\
\text { cope with friendships? }\end{array}$ \\
\hline \multirow[t]{5}{*}{ Bullying/harassment } & $\begin{array}{l}\text { How often } \\
\text { bullied/harassed }\end{array}$ & 1 & $\begin{array}{l}\text { How often this year have you } \\
\text { been bullied or harassed } \\
\text { by student(s) at your } \\
\text { school? }\end{array}$ \\
\hline & $\begin{array}{l}\text { How long } \\
\text { bullied/harassed }\end{array}$ & 1 & $\begin{array}{l}\text { If you were bullied or } \\
\text { harassed this year, how } \\
\text { long did it last? }\end{array}$ \\
\hline & Emotions & 1 & $\begin{array}{l}\text { Which [emoticon] is most like } \\
\text { you when you are being } \\
\text { bullied/harrassed? }\end{array}$ \\
\hline & Safety & 1 & $\begin{array}{l}\text { How safe do you feel from } \\
\text { being bullied/harrassed? }\end{array}$ \\
\hline & $\begin{array}{l}\text { Teachers' } \\
\text { interventions? }\end{array}$ & 1 & $\begin{array}{l}\text { What do teachers usually do } \\
\text { when they see bullying? }\end{array}$ \\
\hline \multirow[t]{5}{*}{$\begin{array}{l}\text { Coping with } \\
\text { bullying/harassment }\end{array}$} & Coping with bullying & 1 & $\begin{array}{l}\text { Overall, how well do you } \\
\text { cope with } \\
\text { bullying/harassment? }\end{array}$ \\
\hline & Emotional responses & 4 & Cry \\
\hline & Assertive responses & 6 & Tell a teacher \\
\hline & Aggressive responses & 3 & Fight back \\
\hline & Passive responses & & Give in \\
\hline \multirow[t]{2}{*}{ Mental health } & Positive mental health & 10 & $\begin{array}{l}\text { [over the past month] I have } \\
\text { shown that I can manage } \\
\text { my own emotional, social } \\
\text { or behavioural situations }\end{array}$ \\
\hline & Mental health problems & 5 & $\begin{array}{l}\text { [over the past month] I have } \\
\text { often felt nervous and } \\
\text { anxious }\end{array}$ \\
\hline
\end{tabular}

